\title{
MARCO LEGAL Y FUNCIÓN DE LA PRENSA EN EL PERIODISMO REPUBLICANO DE 1818. IDEA $Y$ EJERCICIO DE LA LIBERTAD DE IMPRENTA
}

\author{
José Antonio González Pizarro \\ Escuela de Derecho \\ Universidad Católica del Norte \\ Antofagasta
}

Afirma Ricardo Donoso que tempranamente los patriotas de Concepción y Santiago, en la convención suscrita en 1812, declararon la libertad de imprenta y por consiguiente la prensa ayudó a construir una convivencia donde se desterrara el despotismo y la tiranía.

Aquellas nítidas concepciones se repitieron en la Constitución de 1812 y en el decreto de la Junta de Gobierno de 1813.

Precisamente el Reglamento Constitucional de José Miguel Carrera dispuso en su artículo 23 que "La imprenta gozará de una libertad legal,i,para que esto no dejenere en licencia nociva a la relijión,costumbres i honor de los ciudadanos i del país, se prescribirán reglas por el Gobierno i Senado". El decreto de 1813, que comentaremos más adelante, desplegó cómo debían entenderse la libertad de imprenta y las responsabilidades que les cupiere a los autores y editor de los periódicos.

Estos avances en materias constitucionales y legales a favor de una de las libertades públicas más señaladas tuvieron su correlato con el propio despliegue o ejercicio de la libertad de imprenta por los letrados de entonces y por los que arriesgaron el acometer la edición de periódicos de distinta naturaleza.

En ese lapso que caracteriza a la Patria Vieja, la pluma de Camilo Henríquez en gran medida recogió los sentimientos que se confundían con el goce de la libertad de imprenta, entre otros: "El denunciar al público todos los abusos, el propagar las buenas ideas, el intimidar a los malos, el proponer sabios reglamentos y útiles reformas, el extender los conocimientos humanos", como se leía en su Catecismo de los patriotas.

Sin embargo, los aspectos propios del ejercicio del periodismo y de la función de la prensa se verán desplegados a partir del comienzo del Gobierno de Bernardo O'Higgins.

En la administración de O'Higgins, en 1818,una serie de circunstancias hizo que la prensa nacional contara con un respaldo a su propia labor conjuntamente con la presencia de un selecto grupo de "periodistas" que hizo gala del ejercicio de libertad republicana que se empezaba a vivir.

El marco más relevante fue la propia Constitución de O’Higgins, de 1818, cuyo texto reflejaba el nuevo ambiente de libertad. En su artículo 11 declaraba: 
"Todo hombre tiene libertad para publicar sus ideas y examinar los objetos que están a su alcance, con tal que no ofenda a los derechos particulares de los individuos de la sociedad, a la tranquilidad pública y Constitución del Estado, conservación de la religión cristiana, pureza de su moral y sagrados dogmas; y en su consecuencia, se debe permitir la libertad de imprenta, conforme al reglamento que para ello formará el Senado o Congreso".

Si la Constitución reflejaba el espíritu del Gobierno de O'Higgins, se debe consignar la importante presencia de hombres de letras hispanoamericanos que junto con los nacionales dieron muestra de la calidad del periodismo en 1818 y años siguientes. Fueron ellos los que ventilaron los temas más sensibles del rol del periodista y de la función de la prensa, legando un ejercicio responsable, social y orientador para el siglo $\mathrm{XIX}$.

Entre los naturales del continente figuró Antonio José de Irisarri, guatemalteco, influyente consejero de O'Higgins, quien, precisamente ese año,1818, representó al Gobierno en Londres solicitando el famoso empréstito que pesaría en nuestra Hacienda Pública.

El colombiano o neogranadino,como se decía en la época, Juan García del Río. El argentino Bernardo de Vera, ideólogo de 1810, primer diplomático acreditado en Buenos Aires, autor del primer Himno Nacional.

También mantenía, desde 1817, una actividad periodística Mateo Arnaldo Hoevel, sueco naturalizado norteamericano, que habíase destacado por introducir la prensa para editar La Aurora de Chile, en 1812.

Con O'Higgins, como examinaremos, se tuvo una irrestricta libertad de imprenta que, debido a las circunstancia reseñadas, permiten abonar el juicio de Julio Heise de calificarle como "forjador de una tradición democrática".

Los periodistas de 1818 tuvieron cabal sentido del rol de la prensa y de la libertad de opinión y de imprenta, aspectos que discurrieron en sus propios medios informativos.

El jueves 23 de mayo de 1818, Francisco Rivas presentaba El Argos de Chile, periódico semanal que, aunque salía de las prensas gubernamentales, hacía notar que:

"El Editor se propone tratar de los sucesos políticos que conciernen al estado actual de la América: las vicisitudes de que influyan... los imprescindibles derechos del hombre; sin faltar jamás al respeto debido a las autoridades constituidas...el objeto es abrir en su papel un campo al buen gusto de la literatura y política".

En el Número 8 , de 16 de junio, aplaudió la acción de la policía en la mantención del orden. Su ingenio lo demostró en el Número 10, de 30 de julio, en ocasión de proyectarse el semanario El Juguete:

"La historia del "Juguete" es corta. Apareció, insultó, hizo ofertas que no ha cumplido y murió sin que nada lo matase".

En cumplimiento a sus postulados, en el Número 13, de 27 de agosto, fustigó la carencia de un teatro y hospital decentes para Santiago. Cultura y salud eran preocupaciones insoslayables en aquellos años. Se opuso al otorgamiento de las patentes de corsario, por cuanto arruinarían posteriormente a la naciente marina mercante nacio- 
nal. Su exposición es valiosa pues, discutiéndose el tema arriesga una opinión no pesando su calidad de funcionario del Ministerio de Estado, donde se desenvolvía como Secretario de la Sección de Relaciones Exteriores.

La consideración de la prudencia en el manejo informativo la puso de manifiesto cuando trató la partida de la Escuadra Nacional sin rumbo conocido. En su edición de 22 de octubre escribe apesadumbrado que, bajo los españoles y en los inicios de la revolución, "la medida más reservada del gobierno la sabía hasta el último zapatero dos meses antes de su ejecución. A esta mala política debemos mucho males, pero podemos consolarnos con la idea de que nos hemos corregido de esta falta".

El Argos de Chile, cuya edición semanal constaba de ocho páginas, concluyó el 19 de noviembre, alcanzando la edición 22. Rivas, al despedirse, veía con satisfacción la reacción alcanzada ante la circulación de su periódico. El Duende y El Sol eran las respuestas, de cuyos editores reconocíales su "erudición, elocuencia y puntualidad". Acotaba que "el gusto a la lectura debe crearse (y) la emigración de la Europa traerá consigo necesidades y comodidades, de ellas nacerán la industria y el comercio...Al despedirse les suplica que se interesen en fomentar más y más los periódicos que quedan".

El Duende de Santiago llenó la ausencia de un periódico de los días lunes. Su editor Antonio José de Irisarri, calibró la importancia del día, pues, en su opinión, sus noticias serían conversación obligada hasta el día jueves, por lo menos. En el "Prospecto" de 22 de junio, con lenguaje irónico y serio a la vez, establecía su línea editorial:

"Aunque Duende, no pretende meterse en vuestras casas y en vuestros negocios sin pediros, permiso de antemano...No quiero como lo hacen todos los editores, ponderando el servicio que os hago en escribiros un pliego de papel cada ocho días... Detesto de todo corazón los malos usos de la antigüedad, y uno de ellos es entrar lisonjeando a las gentes, llamándolas ilustres, sabias, virtuosas, etc., con el único objeto de hacerles comprar el papel...diré sin rodeos lo que pienso tratar en él, lo que quiero que valga mi trabajo".

De esta manera señalaba su intención de escribir "cuanto me ocurra, bueno o malo sobre el gobierno, sin exponerme a un contraste de fortuna; porque aunque haya libertad de imprenta, como dicen que la hay, no dejo de conocer, que toda libertad debe estar ceñida a los límites del decoro y de la decencia, sin lo cual será un desorden y el peor mal de la sociedad".

Las funciones de la prensa para Irisarri se relacionaban con la visión de conjunto que deseaba impregnarle. El campo lo constituía toda la sociedad, por cuanto "el oficio de los periodistas, amantes de la patria, es el de censores del público. Por lo que no pierden ocasión de afearle lo mal que hace, ni de aplaudirle lo bueno". Luego, la denuncia de los abusos existentes "en todos los pueblos hay abusos, más o menos, según su ilustración y su carácter", también el incursionar en temas políticos era lícito dado que el periodista puede promover reformas de situaciones que él estima, debido a su contacto con el público, como objetables. Y así lo noticiaba :"escribiré sobre nuestros negocios políticos; sobre las reformas que crea conveniente promover".

No obstante, para Irisarri, el conjunto del material informativo que atendiera tales asuntos debía reunir características de confiabilidad: 
"Diré las noticias que tuviera de aquellos sucesos más interesantes que ocurren en nuestro continente, que tengan relación con nuestros negocios, y que me parezcan dignas de fe por el conducto que me las comunique, y por las demás circunstancias que les acompañen".

Posición primera en clarificar la finalidad del oficio y del contenido informativo, en el sentido de noticia, buscando una interpretación de la misma y sus consecuencias en la nación. Sobresale en todo caso la conducta ética al sopesar el carácter y credibilidad del "dato".

Para Irisarri la influencia que ejercía el periodista ante la opinión pública le obligaba a buscar el equilibrio en cuanto a la orientación de los acontecimientos que informaba. Puntualizaba en el número inicial de El Duende de Santiago, de fecha 22 de junio de 1818: "Debeis tener entendido que siendo periodista o escritor, es necesario tener mucha ponderación....además de que no me falten algunas letras".

La condición de la prensa nacional era parte del honor nacional, por cuanto sería imperdonable e insólito "que llegue el caso de mandarse cerrar la imprenta en la capital de Chile por no venderse los impresos". Había que tener en cuenta lo que "se diría en el mundo", si llegase a considerarse en Santiago que el "mueble más ocioso o más inútil" fuera la imprenta.

Preocupación esencial que demostró en el tratamiento de los diversos problemas y cuestiones que demandaban la atención ciudadana, fue para Irisarri, la libertad que se gozaba. En el Número 2, de 2 de junio, estampa:

"La libertad ha sido el único objeto de nuestros empeños desde que comenzaron nuestra gloriosa lucha contra los españoles... pero debemos examinar si gozamos de la libertad que apetecíamos".

Sentencia que ennoblecía la pluma de este redactor que lo fue del primero que vio luz en 1812, sino también del primer periódico de oposición. Lenguaje distintivo del periodista Irisarri que sorprende por su franqueza y que nos conmueve al saber que era el único redactor de la Gazeta Ministerial de Chile y Ministro del Interior. En el Número 3 , de 6 de Julio de El Duende, precisaba que la "ruina de la libertad social ha sido siempre ocasionado por la licencia".

Su estilo punzante tuvo amplia expresión al contestar al editor de El Chileno, en el Número 5 de 20 de julio. Refiere ahí que algún día serán reconocidos los esfuerzos periodísticos de los extranjeros que como él "dedicaron sus vigilias al servicio de su patria".

El sarcasmo casi incomparable de que hizo gala se reflejó en el juicio que le merecieron los periódicos en general existentes en Santiago. En el Número 11, de 21 de septiembre acota irreverentemente que, "nos hallamos muy dispuestos a consignar en los axiomas aquel memorable verso:

\footnotetext{
"Pon tu c....en consejo,

y unos dirán que es blanco,

y otros dirán que es negro".
} 
Frase que sintetiza el pensamiento liberal de un hombre que por mentalidad y funciones era conservador.

La pluma de Juan García del Río se sumó a la de Irisarri al ventilar asuntos similares. Su periódico El Sol, que saldrá los días viernes, a partir del 3 de julio, refería:

"Son incontrastables el poder de la imprenta y de su influjo sobre la civilización, es decir, sobre el desarrollo de las facultades del hombre en el sentido más útil a la sociedad. La existencia sola de la imprenta caracteriza hasta tal punto las luces de una nación, que para informarse de si un país es civilizado o bárbaro, todo lo que hay que preguntar, es lo siguiente: ¿Conoce el uso de la imprenta? ¿Tiene libertad de imprenta?."

En cuanto al material a dar a conocer, estos concernían a las cuestiones políticas, militares, nacionales y extranjeras, siempre y cuando éstas últimas "influyan directa o indirectamente en nuestra suerte".

En los asuntos internos enunciaba que "pasaré revista a nuestro sistema de gobierno, indicando los abusos que puede haber en el y las reformas de que es susceptible". El mismo enfoque mantendría en lo tocante a sus análisis de la educación, la moral, y la legislación nacional, donde expondría "con franqueza mis ideas".

En cuanto a los abusos," que existen en el Estado, lo haré con libertad, diciendo verdades que agradarán a todo el mundo; pero es preciso hacerlo asî".

Para García del Río, el periodista era el verdadero guardián de la libertad nacional:

"El literato, órgano pacífico de la opinión pública (destacado nuestro), debe mantenerse de centinela a la puerta del Estado para recordar continuamente a sus conciudadanos sus derechos y sus deberes, es preciso sacrificar la prudencia al bien del país, pues en lengua republicana son comunes prudencia y debilidad".

¡Insuperable clase magistral sobre el periodismo y su sentido social último expuesta hace 180 años!.

Su perspicacia sobre las cuestiones más urgentes que discutía la ciudadanía, le condujo a escribir, con relación a la demanda de una Constitución por parte de O'Higgins:

"No dudo que la Comisión encargada de trabajar la Constitución provisoria, establezca como ley fundamental la libertad de imprenta en la extensión de la República chilena, pero sin embargo voy a indicar algo sobre esta materia.

La libre comunicación de las ideas, la instrucción y la publicación de los descubrimientos útiles son cosas que interesan a toda sociedad. Cada ciudadano debe a sus asociados sus talentos y sus luces; todo hombre, que ha meditado, les debe el fruto de sus indagaciones y reflexiones; y así en un país bien gobernado tiene el hombre derecho de pensar, de hablar y de escribir...sin ella son perdidos los más sanos talentos para la patria, para la causa de la libertad".

Comentando la disposición gubernamental que liberaba de impuesto la internación de libros, observaba: "Son incalculables las ventajas políticas y morales que saca una nación de la pronta comunicación de las noticias, de los conocimientos e ideas; y 
tanto el público, como los editores de periódicos, deben estar gustosos con esta medida".

En su segundo Número de su periódico, con fecha 10 de julio, prosiguió su exposición sobre la libertad de imprenta, refiriéndose a los "límites que me parecen propios para separar la libertad de imprenta de la licencia de la imprenta". En su concepto, la problemática que encerraba el pendular entre el ejercicio libre y el abuso licencioso en lo que concernía a la imprenta, debía sopesar lo siguiente:

"Autoriza al ciudadano ilustrado para que escriba en todo tiempo contra nuestras leyes, aunque haya sido sancionada siempre que hubiera algo que atente a la verdad, a la moral y al pacto social.

Se empeñe a que critique con valor nuestro código provisorio (alude a la Constitución de 1818 todavía no promulgada) con tal que la censura sea decente y no fomente en una multitud $\sin$ freno el espíritu de rebeldía.

La imprenta libre, para las cabezas exaltadas de los hombres que no saben ser ciudadanos, puede hacer mucho daño...la nación determine poner leyes a la libertad de imprenta.

Todo ciudadano podrá manifestar libremente sus opiniones por medio de la imprenta sobre cualquier materia abstracta sin ninguna responsabilidad.

Para el autor de cualquier escrito, que difame a un hombre es responsable a este de la reputación que lo ha hecho perder: el difamado podría perseguirle...El condenado estará obligado a hacer imprimir a su costa la sentencia, y a distribuirla a satisfacción de su adversario.

Todo escritor de periódico será responsable de su propia redacción en los términos expresados.

Los anónimos que infrinjan la libertad, responderá el editor.

Solo falta tratar de los tribunales que deben fijar los libelos y escritos encendiarios...hablaremos de la excelente institución de los Jurados".

Destaquemos que entre los suscriptores de El Sol figuraba ,en primer lugar, el Supremo Gobierno con 12 ejemplares, Irisarri y Rivas, con 1 ejemplar respectivamente, y García del Río con uno. ras:

En la edición 4, de 24 de julio, García del Río escribe con palabras imperecede-

"Después de la desunión, creo que nada hace tanto mal a la causa que defendemos, como el dejar que ignore la nación los acontecimientos que la conciernen...La rectitud, la buena fe, la franqueza y la sencillez, constituyen la política más sabia para los gobiernos...Si el gobierno calla las noticias desagradables, se aprovechan de esta circunstancia los facciosos y los enemigos que encerramos en nuestro seno, esparcen insidiosamente rumores alarmantes; y como el silencio del gobierno y de los papeles públicos aumenta las sospechas y la desconfianza, se abaten los ánimos, se abultan las especies, y el desaliento llega a ser casi general".

Con motivo de la agresión a un suplementero en calle Santo Domingo, al que se golpeó diciéndole que vendía "noticias mentirosas", García del Río escribió en el Núme- 
ro 5 , de 13 de julio, que "el deber de los editores, es decir lo favorable y lo adverso, y prevenir a tiempo para que se tomen las medidas oportunas para salvar el país".

Para el hombre de letras colombiano, todo patriota debía observar un Decálogo donde figuraba como deberes, el obedecer a las leyes y a la autoridad y "defiende la libertad a costa de tu vida" (№3).

En la visión de García del Río ,la sátira general era útil y aceptable," la personal es inhumana y digna de castigo". En la edición 6, de 7 de agosto, explicitó la defensa del estudio de los idiomas aunque hayan divulgado "libros inmorales e irreligiosos". Con ello defendía las lenguas francesa e inglesa.

El 28 de agosto de 1818 estableció con meridiana claridad el secreto del oficio, en cuanto a la fuente de información, puesto que, a su juicio, era el editor el único responsable ante la ley sobre lo que se publica y se compromete por lo tanto a:

"No insertar en mi periódico ningún artículo comunicado, que no traiga el nombre de su autor...Yo prometo, por mi parte, no hacer uso de esta confianza (destacamos), sino en caso de que el autor deba ser juzgado por abusos de la libertad de imprenta".

La promulgación de la Constitución de 1818 encontró amplia acogida. García del Río expresará, el 30 de octubre, que el día 23 "hará época en los anales de Chile, como que en él se ha puesto la piedra angular de nuestra felicidad, dando a los pueblos una Constitución".

Los artículos que la Constitución contenía sobre la libertad de imprenta concordaban con las ideas sustentadas por el neogranadino.

Empero, además de amparar constitucionalmente la difusión de las opiniones y el establecimiento de las imprentas, el Gobierno de O'Higgins ordenó que se pusiese "en observancia el decreto de 23 de junio de 1813 sobre la libertad de imprenta". Aquello interpretaba y aplicaba el artículo 11 de la Constitución, y decía a la letra:

"Después que en todas las naciones cultas y en todos los tiempos se ha hablado tanto sobre las utilidades de la libertad de imprenta, cuando todos conocen que esta es la barrera más fuerte contra los ataques de la tiranía, y que jamás ha existido un estado libre $\sin$ que todos sus habitantes tengan un derecho de manifestar públicamente sus opiniones, cuando hemos visto que los déspotas han mirado siempre como el medio más seguro de afianzar la tiranía, el prohibir a todo ciudadano la libre comunicación de sus ideas y obligarle a pensar conforme a los caprichos y vicios de su gobierno, y finalmente cuando todos íntimamente conocen que tan natural como el pensar le es al hombre el comunicar sus discursos, sería presuntuoso querer decir algo de nuevo sobre las ventajas... Habrá desde hoy entera y absoluta libertad de imprenta. El hombre tiene derecho de examinar cuantos objetos estén a su alcance; por consiguiente, quedan abolidos las revisiones, aprobaciones y cuantos requisitos se opongan a la libre publicación de los escritos".

Además de referirse a los artículos I, II y III del decreto de 1813, también asumía lo contemplado en los siguientes, como ser en el VIII que rezaba que "convencido el Gobierno de que es un delirio que los hombres particulares disputen sobre materias i objetos sobrenaturales, i no pudiendo ser controvertida la moral que apruebe toda la Iglesia romana, por una escepción de lo determinado en el artículo 1 declara: que los 
escritos relijiosos no pueden publicarse sin previa censura del ordinario eclesiástico i de un vocal de la junta protectora". En cuanto a las responsabilidades, el artículo IX del aludido decreto fijaba:" De todo escrito es responsable su autor, i, si es anónimo, el impresor, quien también debe responder de la publicación de un escrito relijioso sin la censura dispuesta en el artículo $8^{\prime \prime}$.

Todo esto se insertaba en la Gazeta Ministerial de Chile, en su Número 15, Tomo 2, el día sábado 23 de octubre de 1818.

La única limitación era guardar "decoro y honestidad".

El Senado tenía la "suprema tuición y cuidado" de velar sobre aquella libertad, siendo un miembro de esta Cámara, el comisionado para tal fin, dejando sentado que sin su "audiencia" no recae delito alguno de abuso. Una Junta "compuesta de 7 individuos de ilustración, patriotismo e ideas liberales" declararían la existencia de abuso de libertad de prensa. Una vez declarado el delito, le competía a la justicia "conocer el delito y aplicar las penas que correspondan". Ningún tribunal, ningún juez puede proceder a conocer y castigar crimen de esta clase sin la previa declaración de hecho, que debe emitir la Junta Protectora de que hay abuso. Los integrantes de la Junta duraban un año en sus cargos y eran elegidos.

El decreto de O'Higgins que había publicitado la Gazeta consigna que el que atentare "contra la libertad de la imprenta, se entiende que ha atacado la libertad nacional". El documento interpretativo del artículo 11 de la Constitución de 1818 era rubricado por O'Higgins y Joaquín Echeverría.

A modo de información vale dedicar algunas líneas a otros periodistas que pudieron desenvolver sus tareas durante la administración de O'Higgins.

En 1819 Juan Egaña, mentor del referido decreto interpretativo del artículo 11 de la Constitución, publica Cartas Pehuenches. En 1820 Bernardo Monteagudo, secretario de José de San Martín, promotor de las ideas monarquistas, edita El Censor de la Revolución, sugestivo título de un periódico que reflejaba el ambiente de libertad de imprenta. En 1821 Joaquín Egaña, hijo de Juan, da a luz La Miscelánea Chilena. En 1822 Camilo Henríquez edita El Mercurio de Chile, la "primera revista seria de Chile", según el parecer de Raúl Silva castro. Entre sus colaboradores más notables figuraron Manuel de Salas, Bernardo de Vera y Pintado y José Ignacio Zenteno, Ministro de O'Higgins.

Registremos que la única sanción aplicada por O'Higgins sobre un medio de prensa fue a El Independiente, del ciudadano sueco Augusto Brandel quien, en el primer número, de 21 de mayo de 1821, pedía que "se mudase el gobierno actual", refiere Barros Arana..

\section{El 15 de julio el Presbítero Manuel José Verdugo empieza a editar El Chileno.}

Criticó acremente a los periodistas que no eran capaces de indicarle al gobierno las cosas como eran. Para Verdugo, "los papeles públicos son el barómetro con que se mide la ilustración de un país".

En el examen de lo que había sido el ejercicio de la libertad de imprenta reconocía lo realizado en tiempos de José Miguel Carrera, resaltando que: 
"El Semanario Republicano fue el único fruto del reglamento de $1812 \ldots$ no tenía miedo para manifestar sus opiniones pues desagradaba y condenaba las operaciones de los hombres más temibles de aquella época. El pagó al fin su franqueza pues fue víctima del resentimiento de los Carrera".

Restó mérito a La Aurora de Chile y al Monitor Araucano por cuanto ambos periódicos se publicaban "bajo la misma dependencia del gobierno".

Las opiniones de Manuel José Verdugo constituyeron clases de genuino periodismo. Su última intervención fue para dejar sentir su voz por la poca injerencia de los nacionales en el campo del periodismo:

"Me atrevo a salir a pública palestra, para defender que hay chilenos que pueden escribir, y que son celosos de la fama de su patria. Si hay libertad de imprenta no es honor nuestro que sólo usen de ella los que no nacieron en nuestro suelo".

Esta orientación jurídico-política de O'Higgins, en materias de libertad de imprenta, fue reafirmada por el Gobierno de Ramón Freire. Con la firma de su Ministro Mariano de Egaña, adicionó a lo establecido en materias de imprenta, la ley de fecha de 18 de junio de 1823 , donde los acápites más significativos, en lo que nos interesa subrayar, son los referidos al artículo 1: "Que la lei de imprenta contenida en el decreto de 23 de junio de 1823, es una antigüedad preciosa de la revolución i debe conservarse en todas sus partes"; y al artículo 10 "Que los abusos de la prensa se dividirán en tres clases: leves, graves i gravísimos; i las penas serán proporcionadas al grado de la ofensa".

1818 simbolizó una de las páginas decisivas en el acontecer político-militar, pero también constituyó un hito en la conjugación del contexto jurídico con el verdadero despliegue de la prensa, donde ésta combinaba posiciones oficiales y disidentes y nos ilustra de uno de los elementos patrimoniales más distintivos del espíritu nacional: su periodismo.

\section{BIBLIOGRAFIA}

Luis Valencia Avaria, Anales de la República. Tomos I y II Actualizados.

Ed.Andrés Bello,1986.

Simon Collier, Ideas y Política de la Independencia Chilena 1808-1833.

Ed.Andrés Bello,1977.

Ricardo Donoso, Las ideas políticas en Chile. Fondo de Cultura Económica, México, 1946.

Archivo Nacional:Archivo de Bernardo O'Higgins. Santiago, 1958, Tomo XIII.

Guillermo Feliú Cruz (Editor), Colección de Antiguos Periódicos Chilenos.

Biblioteca Nacional, 1958.

Raúl Silva Castro, Prensa y Periodismo en Chile 1812-1956. 
Revista de Derecho - Universidad Católica del Norte - Sede Coquimbo - 1998

Ed. Universidad de Chile,1958.

Diego Barros Arana, Historia Jeneral de Chile

Rafael Jover Editores,Santiago,1894,Tomos XI,XII,XIII.

Ricardo Anguita, Leyes promulgadas en Chile.Desde 1810 hasta el $1^{\circ}$ de Junio de 1912. Imprenta, Litografía i Encuadernación Barcelona, Santiago, 1912. Tomo I. 